
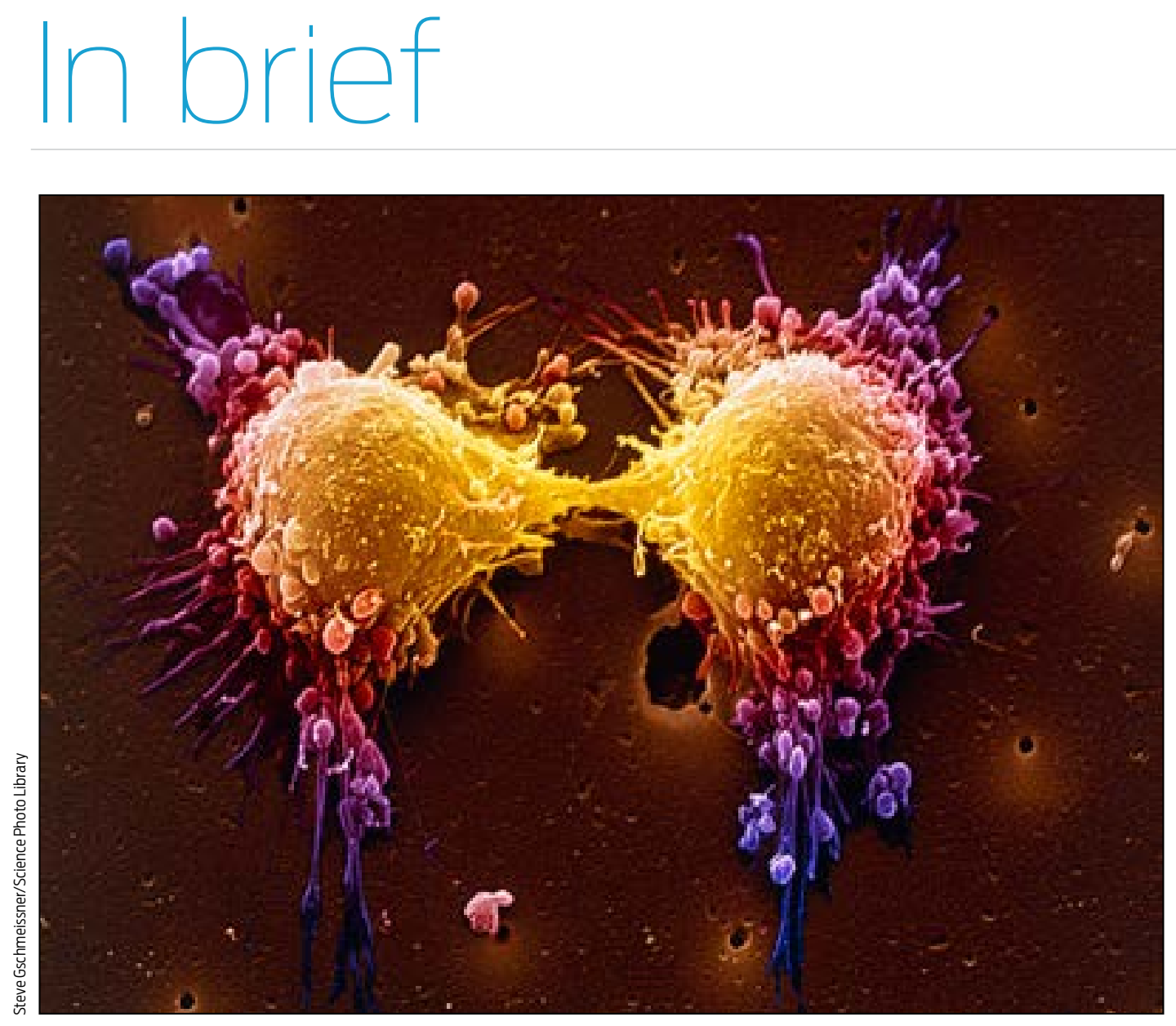

A coloured scanning electron micrograph shows two prostate cancer cells in the final stage of cell division (cytokinesis). During this stage, the cells' cytoplasm divides. Here the cells are joined by a thin cytoplasmic bridge. Magnification unknown.

\title{
From the Consumers Health Forum of Australia
}

\section{Australian health care - out of pocket and out of date?}

In recent months, diverse organisations have suggested that, without profound change to ensure affordability, Medicare's role as a universal insurer underwriting feefor-service medicine is nearing an endgame. The Consumers Health Forum (CHF) has added its voice to the chorus on the health affordability dilemma with its "Hip Pocket Pain" campaign, highlighting the rising burden of out-of-pocket health care costs on patients, particularly those with chronic illness.

The Committee for Economic Development of Australia (CEDA) and the Grattan Institute have each produced reports touching on the same theme: the unsustainable rise in the cost of health care under current funding arrangements. CEDA's report, Healthcare: reform or ration, proposes measures to make health care more efficient and performancedriven - such as aggregating funding at the level of the individual and unleashing competition between health insurance funds. The Grattan Institute report, Budget pressures on Australian governments, suggests the surging growth in health spending - up by $74 \%$ in real terms over the past decade - is making the option of deep cuts or deep change inescapable. In the wake of these conclusions, revelations of the growth in financial burden faced by many individual patients underscore the political case for change.

The CHF's appeal for change certainly does not mean abandoning our commitment to the principle of equity of access to quality health care for all, regardless of means. But, along with an increasing number of scholars and practitioners, the CHF questions

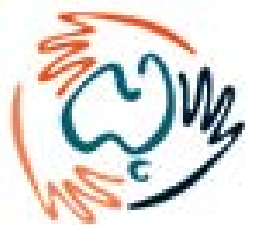

Consumers

Health Forum of Australia

Carol Bennett

Chief Executive Officer

Consumers Health Forum of Australia

doi: 10.5694/mjal3.10582 whether the throughput-driven system fuelled by fee-for-service, largely unrestrained by performance and outcome measures, is best for the patient or the purse strings.

The increasing incidence of longterm chronic illness and providers' and consumers' swelling appetite for the latest in medical advances are among the forces pitting universal health care against budgets already tightened by population ageing.

The CHF believes it is time for Australia to consider changes that will better shape health care according to best evidence and practice, to empower consumer choice by means of truly competitive purchasing entities, and to reward practitioners on the basis of outcomes. The result may mean the demise of Medicare in its current form, but its legacy of universal access could survive. 


\section{Seven-year hitch for prolapse surgery}

Surgeons and patients may need to lower their expectations about pelvic floor surgery following the release of results from the extended Colpopexy and Urinary Reduction Efforts (CARE) trial, published in JAMA. The trial followed up participants in the original 2-year CARE study at 5 years and 7 years after abdominal sacrocolpopexy, either with or without concomitant urethropexy. Of 215 patients, 104 had both procedures together and 111 had sacrocolpopexy alone. The authors found high rates of pelvic organ prolapse (probability of 0.48 with urethropexy v 0.34 without) and urinary incontinence (probability of 0.62 with urethropexy v 0.77 without) during 7 years of follow-up. An accompanying editorial concluded that the results call into question "the designation of the abdominal sacrocolpopexy as the criterion standard for prolapse repair" and that "operations for pelvic organ prolapse also may be vulnerable to the normal wear and tear of ageing and activities of daily living".

JAMA 2013; 309: 2016-2024. JAMA 2013; 309: 2045-2046

\section{Vaccine confidence essential for eradication}

The Vaccine Confidence Project has published results of its 1-year study of media coverage of immunisation in a recent edition of The Lancet, highlighting the importance of early detection of and intervention in vaccine hesitancy, refusals and disease outbreaks. The authors used the HealthMap automated data collection system to analyse 10380 reports from 144 countries obtained between 1 May 2011 and 30 April 2012. They found that $69 \%$ of reports (7171) contained positive or neutral content, and 31\% (3209) contained negative content. "The importance of listening to the public throughout the design and implementation of vaccine programmes and research trials cannot be understated", the authors wrote. "Even more important is acting on what is learned and acting early." An accompanying editorial concluded that: "Speed might be essential to achieve disease eradication, but moving quickly enough will only be possible by first building strong public belief and confidence in immunisation."

Lancet 2013; 13 May (online)

doi: 10.1016/S1473-3099(13)70108-7

doi: 10.1016/S1473-3099(13)70131-2

\section{From the MJA archives}

\section{MJA 1932: 9 January (edited extract)}

\section{The poliomyelitis danger}

A considerable increase in the number of poliomyelitis infections is taking place and the call is for watchfulness, careful examination and readiness to institute proper treatment ... Poliomyelitis, when not recognised and treated in the early stages, is ... fraught with such dire and lasting results that the main facts must be stated in this place ... The medical practitioner is, of course, not the only person concerned - he cannot make a diagnosis until he sees the patient.
The general public must be taught that feverish attacks in children must not be treated lightly, but that medical advice should be sought ... It rests with the general practitioners to make this work effective ... In no disease in the whole gamut of human suffering does so much depend on the vigilance and insight of the medical attendant. If any doubt should arise in his mind, or if he should feel that he is not competent to make a diagnosis, he should without delay seek the assistance of someone who has studied the subject and is able to help him. There must be no temporising and no uncertainty.

Editorial

\section{Depression screening not justified}

A systematic review of evidence has led the Canadian Task Force on Preventive Health Care to recommend not routinely screening for depression in adults in primary care settings in the absence of clinical suspicion, as reported in CMAJ. The reviewers found that in adults at average risk the effectiveness of screening tools was "uncertain"; that, given people with mild depression may not benefit from treatment, screening could lead to unnecessary treatment; and some patients would stop treatment before remission, in which case screening would not lead to benefit. Additionally, the review also recommended that screening not be undertaken in adults at increased risk of developing depression. "One cannot assume that screening will benefit people at increased risk simply because they may have a higher incidence and prevalence of depression", the authors wrote. An accompanying commentary said the number of false-positive screens with current assessment tools was too high, and the follow-up required was too time-consuming to justify screening in primary care settings.

CMAJ 2013; 13 May (online). doi: 10.1503/cmaj.130403 doi: 10.1503/cmaj.130634

\section{Keep consent forms simple}

Simplifying research consent forms increases understanding of trials and their consequences for parents and their children, a study in JAMA Pediatrics reports. The authors conducted an observational study from January 2010 to June 2012 with 640 parents of children scheduled to receive elective surgery at a large tertiary children's hospital. Parents were randomly allocated to receive information about a hypothetical pain trial presented in one of 16 consent documents containing different combinations of five communication strategies — length, readability, processability (formatting), graphical display and supplemental disclosure. The authors found that, while all five strategies improved understanding, the three most important factors were eighth-grade reading level, improved formatting, and the use of graphical elements. An accompanying editorial stated that "the consent document should be reimagined to become as simple and concise as possible".

JAMA Pediatr 2013; 13 May (online) doi: 10.1001/jamapediatrics.2013.1385 doi: 10.1001/jamapediatrics.2013.152 